\title{
Raphaële Andrault
}

La raison des corps : Mécanisme et science médicale (Paris: Vrin, 2016), pp. 220, €12, ISBN 9782711626311.

This book takes as its starting point an epistemological reconstruction of the fundamental tension between vitalism and mechanism in the history of biomedicine as discussed by Jean Rostand (1894-1977) and Georges Canguilhem (1904-1995), and produces an archaeological inquiry into the strong opposition that lies at its classical origins, namely the philosophy, medicine, and anthropology of the seventeenth and eighteenth centuries. Raphaële Andrault brilliantly succeeds in shedding new light on this structural antagonism. Using material from René Descartes's philosophy of living beings as automata, from William Harvey's medical discovery of blood circulation, and from their respective legacies, her reconstruction reaches its culmination in the analysis of the debate between Georg Ernst Stahl and Gottfried Wilhelm Leibniz. And yet, the book is not a mere description of conflicting and disconnected views, but also seeks to track the ways in which mechanical and animistic approaches to living beings became integrated.

Probing into early-modern mechanics through a detailed and accurate historical exploration, the culmination of which is contained in the Encyclopédie's article "méchaniciens" (p. 10), the author discloses the limitations of earlymodern mechanical understanding, which has traditionally been considered a blind spot for biological knowledge. Some unexpected issues emerge (p. 191), however, as an epistemologically rich divergence is shown to have existed between what mechanics entailed when applied to life (i.e., those cases in which mechanics helps explain the very features of living bodies), and its successes in explaining life by going beyond the intrinsic limitations of mechanics itself (p. 9). In other words, mechanics plays a crucial function even when it seems insufficient for biological knowledge, as it grounded the method of early-modern investigations of life.

While presenting a strong example of the mechanization of living beings, Descartes's philosophy constitutes for Andrault the point of departure for investigating this double state of mechanics. In a well-known passage in the Sixth Meditation, where Descartes tackles several paradoxes while determining the characteristics of the mind-body composite, the exceptional cases of amputation or dropsy reveal not just the limitations of mechanics for an understanding of life (according to which health could only be defined as an extrinsic denomination), but they show the persistence of teleological conceptions even within a mechanical explanation of life (pp. 182-183). Andrault expands on this theme and reconstructs the consequences of a mechanization 
of medicine for a series of topics, moving from anatomy (Chapter 1) to the usus of organs (Chapter 2), finality (Chapter 3), and therapeutics (Chapter 4). In the last chapter, she extends this history to a segment of the twentieth-century debate concerning the phenomenon of life.

In her first chapter, "Le legs cartésien. Mécanisme et observation anatomique," Andrault presents the connections between anatomical insights and mechanical philosophy that emerge from Descartes's philosophy. Ambiguities quickly surface: Descartes's mechanics relies on anatomy to describe the invisible parts of the body, but at the same time, it limits observation, as sensible effects have insensible causes (pp. 37-41). Given that, for Descartes, the function creates the organ, his physiology denies that anatomy serves to construct models of explanation, restricting its empirical use to finding the aetiology of living functions. At the same time, alternative interpretations of the role of anatomy emerge, which either foster or restrict empirical research (p. 61), and ultimately lead to a variety of scientific "architectures."

In Chapter 2, "Les fonctions du visible. L'analyse et l'usage des organes," Andrault analyses one result of the application of mechanical philosophy to anatomy, namely the new relationship it creates between the uses and functions of organs. A fitting example is Nicholas Steno's definition of the heart as a muscle, which implied a rejection of traditional taxonomies grounded on a different comprehension of the functions of organs. Steno favored instead an anatomical analysis of the structure of organs, which helped to disclose their usus. By contrast, according to the Galenic tradition, the function of organs defined their purpose and finality, which reversed the direction of physical causation, and rendered any explanation difficult (pp. 89-91). The new anatomical analysis instead selected the structure of organs as the means of explaining their activities (pp. 92-93). Applied to anatomy, mechanics thus helped the process of distinguishing between the Galenic usus partium and the modern usus fabricae, the latter producing a more exhaustive account of organs (p. 101).

A second result is the disqualification of final causality, which is the subject of Chapter 3, entitled "Les fins du vivant. Le corps animal comme machine divine." Andrault there investigates the reasons for which Leibniz objected to the exclusion of final causes, all the while acknowledging the inherent ambiguity involved in defining finality in living beings. Interestingly, Leibniz's reintroduction of final causes, however, provided a further justification for the mechanical comprehension of bodies typical of Cartesianism (p. 111), as it related functions to structures and rejected the identification of particularities and final causes, as organs display a multiplicity of functions. Leibniz's recovery of final causes is, thus, shown to have developed within mechanics (p. 122). 
This point of view provides the background to the debate between Stahl and Leibniz over animism versus mechanism, which Andrault analyzes in Chapter 4, "La thérapeutique mécaniste. Le corps humain comme organe de lâme." The two men's opposition was concerned more with the psycho-physiological relationship between the corps propre and the soul than with the mechanical nature of organs in themselves. Both thinkers focused on the relationship between the soul and the body. Yet, while Leibniz privileged the role of the disposition of organs and the mechanics of the body, Stahl highlighted the role of the soul in controlling the body. This opposition entailed differences also in defining perception (p. 142), medicine, and therapeutics (pp. 149-153). However, a finalistic argumentation may be detected even in the mechanistic approach, not insofar as it ascribes a feature of the soul (as in Stahl), but as the telos of the entire body (p.160). As a result, the difference between mechanism and animism resides in four related issues: the medical utility of anatomy, diseases as natural states, the possibility for treating organs or the soul-body connection, and the validity of mechanical analogies.

The final chapter, "Lectures de Canguilhem. La philosophie mécaniste," focuses on contemporary receptions of this debate and retraces the differences and the similitudes between mechanism and vitalism. Rather than choosing between these alternatives, Andrault chooses a more promising route by investigating the nuances of mechanism in early modernity, as it contained the seeds of the bio-medical revolution, and of vitalism itself (p. 189). By revealing a multiplicity of meanings of 'mechanism' (pp. 197-198), Andrault sheds light on its crucial role in the history of medicine. Her book, which is of paramount importance for philosophers and historians of science and bio-medicine, ultimately lays bare the salient features of early-modern discussions about finality in living bodies, individuality, organicity, and practical medicine.

\section{Fabrizio Baldassarri}

Università degli Studi di Padova fabrizio.baldassarri@unipd.it 